\title{
Optimisation of production processes with the use of the modelling and simulation method
}

\author{
Dariusz Plinta ${ }^{1, *}$, and Patrik Grznar ${ }^{2}$ \\ ${ }^{1}$ University of Bielsko-Biala, Department of Industrial Engineering, Willowa 2, 43-309 Bielsko-Biala, \\ Poland \\ ${ }^{2}$ University of Zilina, Department of Industrial Engineering, Univerzitná 1, 01026 Zilina, Slovakia
}

\begin{abstract}
The paper presents an application of the modelling and simulation method for finding an optimum solution related to designing production processes. Using simulation in connection with optimization makes it possible to check almost all admissible variants of the proposed improvements comparatively quickly in order to evaluate them and to choose the best solution. The paper presents how a simulation model is created and shows an example of multi-criteria optimization.
\end{abstract}

\section{Introduction}

Efficient analysis of production processes requires meeting two conditions. The first one is related with collecting information about the realised processes, and the second one is concerned with the use of various theories and techniques which help to find an optimal solution. Proper planning of research is necessary to find all possible solutions, and, first of all, to set proper estimation criteria. In the projects related to modelling and simulation, we often have many ideas for improvements before we start creating a model, and additionally, after the first simulation of the current state and after the following simulations, many new suggestions for improvements appear. In such analysis, many variations of improvements come into being and there are too many possible combinations of their implementation. If it is not possible to test all determined arrangements, we only analyse the variants, which are chosen on the basis of our opinion, intuition and our knowledge about the research object [1-3].

Nowadays competitive environment requires utilization of new software systems for design, testing, process planning, manufacturing and assembly. Application of such a digital framework for modelling and simulation of production allows to achieve higher quality, and efficiency [4].

Production processes modelling is mainly based on the information collected in a static data base. The information, like standard process time, material norms, information about using resources, working conditions (ergonomics) [5] or costs of machine usage per hour, means of transport usage [6], is rarely updated. The changes in production systems, which happen regularly and which will appear in the future are not often analysed and collected in such a data base. By using the modelling and simulation packet integrated with this base,

\footnotetext{
* Corresponding author: dplinta@ath.bielsko.pl
} 
we can create a dynamic data base, which allows us to analyse the effects of different changes and improve the production process [7-9] - Fig.1.

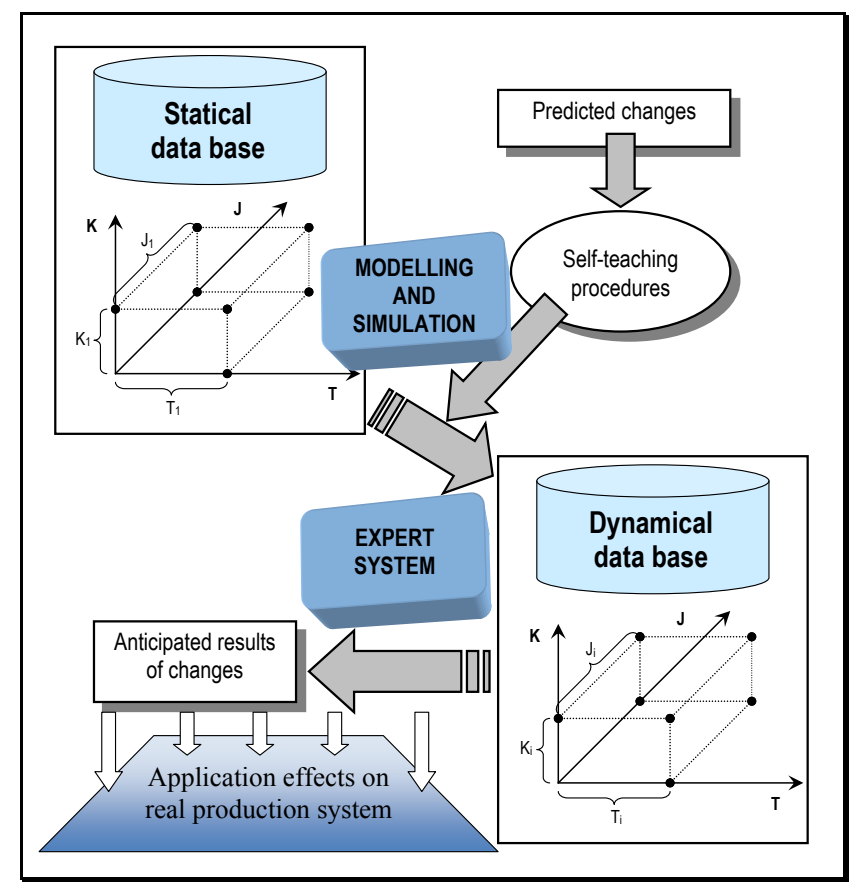

Fig. 1. Production management aided by the modelling and simulation technique.

Estimation and selection of the best variant for implementation can be realized by applying multi-criteria estimation methods and tools, using deterministic or fuzzy criteria [10]. An example of such a method is presented in the following point of this paper.

\section{Estimation and selection of a variant of manufacturing process run for realization}

In the example for estimation and selection production process, which is presented below, estimation according to the Yager method was proposed and applied [10]. Input data for this analysis include:

- $\quad$ number of criteria $(m)$,

- number of variants of the manufacturing process run $(n)$,

- $\quad$ matrix of individual criteria validity $\left(B=\left[b_{i j}\right]\right)$,

- $\quad$ matrix $C=\left[c_{i j}(e)\right]$ with evaluation of the $i$-variant according to $j$-criterion, which is prepared by experts.

All chosen experts creates a validity estimation matrix of the criteria according to the Saaty's method in which experts compare all pairs of the defined criteria [11]. In the next step one summary matrix is created from all validity criteria. For the summary matrix there the eigenvector $Y$ is calculated by completing the following equation:

$$
B Y=\lambda_{\max } Y
$$

where: $B$ - matrix of the summary criteria validity,

$Y$ - eigenvector,

$\lambda_{\max }-$ maximum eigenvalue of matrix $B$. 
The eigenvector has many coordinates, which have to meet the following formula:

$$
\sum_{j=1}^{m} y_{j}=m
$$

where: $y_{j}-j$-coordinate of the eigenvector $Y$.

The coordinates of the eigenvector, which are called weights, represent the validity of the defined criteria (a criterion with a higher value of weight is more important). By means of the involution method, the eigenvalue and the eigenvector can be determined. In the below analysis, this task was realized with the numerical procedure, which was written in the Pascal language.

The final estimation is realized by averaging the evaluations proposed by all chosen experts, and calculated by the following formula:

$$
c_{i j}=\frac{1}{p} \sum_{e=1}^{p} c_{i j}(e)
$$

where: $p$ - number of experts.

The final results for each variant are presented by the normalised decisions function:

$$
\begin{gathered}
d_{j}=\sum_{j=1}^{m} c_{i j}{ }^{y_{j}} / w_{i} \\
d_{1}=c_{11}^{y_{1}} / w_{1}+c_{21}^{y_{1}} / w_{2}+\ldots+c_{n 1}^{y_{1}} / w_{n} \\
d_{2}=c_{12}^{y_{2}} / w_{1}+c_{22}^{y_{2}} / w_{2}+\ldots+c_{n 2}^{y_{2}} / w_{n} \\
\ldots \ldots \ldots \ldots \ldots \ldots \ldots \ldots \ldots \ldots \ldots \ldots \ldots \ldots \ldots \ldots \ldots \ldots \ldots \ldots \ldots \ldots \ldots \ldots \ldots \ldots \ldots \ldots \ldots \ldots \ldots \ldots \\
d_{m}=c_{1 m}^{y_{m}} / w_{1}+c_{2 m}^{y_{m}} / w_{2}+\ldots .+c_{n m}^{y_{m}} / w_{n}
\end{gathered}
$$

The result is the optimum decision, which is shown as the best solution fulfilling all the defined criteria:

$$
D=D_{1}+D_{2}+\ldots+D_{n}
$$

In the presented method, the optimum decision is the minimum - the smallest $i$-th component among particular decisions $d_{1}, d_{2}, \ldots, d_{m}$.

$$
D_{i}=\min _{j} c_{i j}^{y_{j}}
$$

The best variant of the analysed production process, taking into account the chosen criteria, is the variant corresponding with the largest value, that is the highest degree of belongingness value.

$$
D_{\text {rac }}=\max _{i} D_{i}
$$

The use of this method is simple and effective. By taking into account the validity estimation of individual criteria and by calculating their weights, it is possible to evaluate the defined variants of the analysed production process and to create their ranking. It is very helpful in planning simulation experiments and also in improving production processes.

The analysis presented below is connected with garden furniture production processes of different tables, chairs and benches. The input materials for such furniture were divided into three groups: elements, which are made of wood, metal and common parts for all 
products. The common materials are ordered collectively, without specifying the target product in which they will be used. After the production process the packed furniture is shipped directly to wholesalers and shops.

The main purpose of the analysis was to determine production capabilities and to test the determined possibilities for improvement.

The following assumptions were made:

- time of realizing production operations were determined by constant time or by statistical distribution (randomly generated process time),

- the planned production volume was determined according to sales forecasts,

- demand for particular materials was defined according to the planned production volume,

- distances between suppliers and the firm, and also between the firm and its customers (wholesalers and shops) were specified,

- $\quad$ transport type, times and unit costs of transport (per km) were determined,

- companies for possible cooperation have been identified (companies, which will cooperate during materials preparation and assembly),

- simulation parameters were defined.

An analysis of the current state of production process was analysed in the first step. The resources availability has been assessed and on the basis of the information from simulation report a calculation of costs was performed. In subsequent simulations, the most possible changes were checked, which are planned for application. For example, the production of table tops was outsourced. This means moving several operations to subcontractors. Such cooperation will make it possible for the analysed company to achieve shorter lead time. Table 1 includes the description of the most possible simulated variants.

Table 1. Description of simulation variants.

\begin{tabular}{|cl|}
\hline $\begin{array}{c}\text { Number } \\
\text { of } \\
\text { variant }\end{array}$ & Description \\
\hline 1 & $\begin{array}{l}\text { All manufacturing processes are realized directly in the company - all parts are } \\
\text { manufactured and all final products are assembled and sent to customers (wholesalers } \\
\text { and shops). }\end{array}$ \\
\hline 2 & $\begin{array}{l}\text { Special table tops, which are made of plastic or stone, will be bought directly from a } \\
\text { new supplier. }\end{array}$ \\
\hline 3 & $\begin{array}{l}\text { Establishing cooperation with a company, which will provide pre-processed of wood } \\
\text { components. }\end{array}$ \\
\hline 4 & $\begin{array}{l}\text { Extending the range of final products with components of currently manufactured } \\
\text { furniture (creating a garden furniture system). }\end{array}$ \\
\hline 5 & Establishing cooperation with a company, which designe and arrange gardens. \\
\hline 6 & Improving the manufacturing process - modernization of critical machines and devices. \\
\hline
\end{tabular}

It was possible to compare the results from different variants of the proposed change with the analysed production process by comparing three criteria: usage of the possessed means of production, production costs and production volume (Table 2). The Yager's method was applied for this purpose.

The estimation of the proposed criteria and simulation variants was conducted by three experts: one from the manufacturing department, second from the quality department and third form the cost-analysis section (Fig. 2).

The best results were achieved in variant 6 (Table 3) with all proposed changes. Improvements directly in manufacturing (machines and tools) will increase production about $10 \%$. But, it is also necessary to extend the range of final products and to move some processes in outsourcing (manufacturing of the special table tops). 
Table 2. Simulation results

\begin{tabular}{|l|ccccccc|}
\hline Criterion & Variant: & $\mathbf{1}$ & $\mathbf{2}$ & $\mathbf{3}$ & $\mathbf{4}$ & $\mathbf{5}$ & $\mathbf{6}$ \\
\hline \multirow{2}{*}{$\begin{array}{l}\text { Average utilization } \\
\text { of workplaces [\%] }\end{array}$} & Chairs & 33.2 & 31.0 & 31.5 & 34.3 & 34.4 & 37.6 \\
\cline { 2 - 8 } & Tables & 50.1 & 48.9 & 47.5 & 54.6 & 54.2 & 57.0 \\
\hline $\begin{array}{l}\text { Production costs } \\
\text { [PLN] }\end{array}$ & Chairs & 244.43 & 224.50 & 232.50 & 231.05 & 210.33 & 200.65 \\
\cline { 2 - 9 } & Tables & 401.14 & 490.54 & 469.24 & 486.55 & 470.45 & 470.63 \\
\hline $\begin{array}{l}\text { Produced volume } \\
\text { [pieces/week] }\end{array}$ & Chairs & 123 & 135 & 137 & 135 & 132 & 158 \\
\cline { 2 - 9 } & Tables & 164 & 177 & 180 & 180 & 185 & 200 \\
\hline
\end{tabular}

\begin{tabular}{|c|c|c|c|c|c|c|c|c|c|c|c|}
\hline \multicolumn{4}{|c|}{ Expert 1} & \multicolumn{4}{|c|}{ Expert 2} & \multicolumn{4}{|c|}{ Expert 3} \\
\hline & k1 & k2 & k3 & & k1 & k2 & k3 & & k1 & k2 & k3 \\
\hline k1 & 1 & 1 & 2 & k1 & 1 & 0.5 & 0.25 & k1 & 1 & 4 & 0.3333 \\
\hline k2 & 1 & 1 & 2 & k2 & 2 & 1 & 0.5 & k2 & 0,25 & 1 & 3 \\
\hline k3 & 0.5 & 0.5 & 1 & k3 & 4 & 2 & 1 & k3 & 3 & 0.3333 & 1 \\
\hline
\end{tabular}

\begin{tabular}{|c|c|c|c|}
\hline \multicolumn{4}{|c|}{ The summary matrix of the criteria } \\
validity \\
\hline & $\mathbf{k} 1$ & $\mathbf{k 2}$ & $\mathbf{k 3}$ \\
\hline $\mathbf{k} 1$ & 1 & 1.8333 & 0.8611 \\
\hline $\mathbf{k} 2$ & 0.5455 & 1 & 1.8333 \\
\hline $\mathbf{k} 3$ & 1.1613 & 0.5455 & 1 \\
\hline
\end{tabular}

Fig. 2. Criteria validity estimation by particular experts.

Table 3. Multi-criteria estimation of variants.

\begin{tabular}{|c|c|}
\hline $\begin{array}{l}\text { Co- } \\
\text { ordinates of } \\
\text { eigenvector: }\end{array}$ & $Y=\left[\begin{array}{l}1.1554 \\
0.9924 \\
0.8523\end{array}\right]$ \\
\hline $\begin{array}{l}\text { The } \\
\text { function of } \\
\text { optimum } \\
\text { decision: }\end{array}$ & 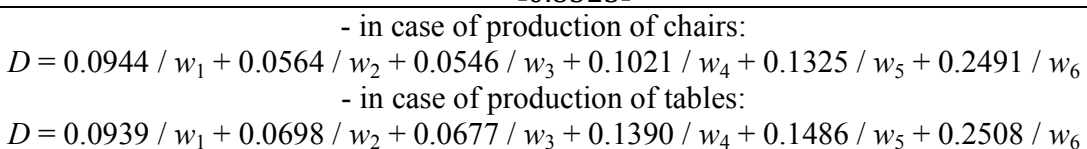 \\
\hline \multirow{2}{*}{$\begin{array}{l}\text { Preferred } \\
\text { solution: }\end{array}$} & Chairs: Variant 6 with the largest value in the function of optimum decision: $\mathbf{0 . 2 4 9 1}$ \\
\hline & Tables: Variant 6 with the largest value in the function of optimum decision: $\mathbf{0 . 2 5 0 8}$ \\
\hline
\end{tabular}

\section{Conclusions}

At the beginning of every analysis it is necessary to define input parameters of the analysed system, and also the expected output parameters, which will be the goal of the conducted analyses. We can define two cases here. In the first one, simulation for checking behaviour of the system is realized for the defined input parameters. In the second case, we have a set of different input data, with a problem of finding the optimum. It is connected with finding such input data which gives the best result according to the assumed criteria. In this approach, the problem is to find the optimum solution. It is necessary to plan particular steps of research properly to find all possible solution variants, and first of all to set the criteria for evaluation of the proposed variants in a proper way. 
Determining several criteria for the evaluation of the modelled production process variants sometimes makes it impossible to find the best solution. Simulation does not give us optimal solution, but it is a very good tool, which supports us and enables to quickly test different variants of the analysed production process. Thanks to the application of the optimisation method, like the Yager's method, it is then possible to indicate the best solution.

Thanks to the simulation:

- different directions of the proposed changes related to the production process can be compared,

- $\quad$ variants can be evaluated from the point of view of different criteria like for example utilization of resources, production costs and production volume.

The presented example confirm the usefulness of the modelling and simulation method in solving problems concerned with optimization of production processes.

\section{References}

1. J. Basl, Analysis of Industry 4.0 Readiness Indexes and Maturity Models and Proposal of the Dimension for Enterprise Information Systems. In: Research and Practical Issues of Enterprise Information Systems (Cham - Springer, Poznań, 2018)

2. Ch. Hitz, M. Vojvodic, J. Basl, Designing for consistency of evaluation in enterprise governance of IT (EGIT). In: Conference Proceedings - 10th \& 11th International Conferences on New Challenges in Management and Business (NCMConferences, Dubaj, 2018)

3. D. Montgomery, Design and Analysis of experiments (Wiley, New York, 1997)

4. D. Plinta, M. Krajčovič, Applied Computer Science, 13, 2 (2017)

5. L. Dulina, Ergonomics analysis of a digital factory with the support of augmented reality. In: Chosen applications of computer modelling in mechanical engineering (Pearson Education Limited, London, 2015)

6. V. Vavrík, M. Gregor, P. Grznár, Procedia Engineering, 192 (2017)

7. M. Bučková, M. Krajčovič, D. Plinta: Use of dynamic simulation in warehouse designing. In: Intelligent systems in production engineering and maintenance, (Cham Springer International Publishing, 2019)

8. A. Gola, Eksploatacja i Niezawodnosc-Maintenance and Reliability 21, 1 (2019)

9. W. Kelton, Simulation with Arena (McGraw-Hill, Sewickley, 2014)

10. R. Yager, D. Filev, Essentials of fuzzy modelling and control (John Wiley \& Sons, New York, 1994)

11. T.L. Saaty, The Analytic hierarchy processes (McGraw-Hill, New York, 1980) 